\title{
Gains from Wage Flexibility and the Zero Lower Bound*
}

\author{
RoBerto M. BILLI† and JoRdi GaLít
}

$\dagger$ Sveriges Riksbank, Stockholm, Sweden. (e-mail: roberto.billi@riksbank.se)

$\$$ †REI, UPF and Barcelona GSE, Barcelona 08005, Spain. (e-mail: jgali@crei.cat)

\begin{abstract}
We analyse the welfare impact of greater wage flexibility in the presence of an occasionally binding zero lower bound (ZLB) constraint on the nominal interest rate. We show that the ZLB constraint generally amplifies the adverse effects of greater wage flexibility on welfare when the central bank follows a conventional Taylor rule. When demand shocks are the driving force, the ZLB implies that an increase in wage flexibility reduces welfare even under the optimal monetary policy with commitment.
\end{abstract}

\section{Introduction}

Most mainstream economists view wage rigidity as an undesirable feature for an economy, one that is likely to hamper macroeconomic stability and cause a high and volatile unemployment rate. The perceived costs of wage rigidity rely on a logic based on the familiar labour market diagram found in introductory textbooks: a decrease in wages should offset, at least partly, the negative effects on employment (and output) of any adverse aggregate shock that reduces labour demand. If wages are rigid and that adjustment does not take place (or it is slow) the negative employment and output effects of adverse shocks are likely to be amplified and unemployment will rise, at least temporarily. ${ }^{1}$

In the General Theory, Keynes (1936) already called into question the previous logic, which he associated with 'classical' economics, and deemed it irrelevant to understand the workings of modern economies. In his view, the wage level does not have a direct role in the determination of employment. The latter is instead determined by aggregate demand

JEL Classification numbers: E24, E32, E52.

*We thank Pierrick Clerc, Yoon J. Jo, Michael Kumhof, Cristina Manea, Ales Marsal, Francesco Zanetti and two anonymous referees for useful comments. Galí acknowledges financial support from the Spanish Ministry of Economy and Competitiveness, through an I+D Grant (ECO2017-87827) and the Severo Ochoa Programme for Centres of Excellence in R\&D (SEV-2015-0563). The views expressed herein are solely the responsibility of the authors and should not be interpreted as reflecting the views of Sveriges Riksbank.

${ }^{1}$ See, for example, Hall (2005) and Shimer $(2005,2012)$ for a discussion of the role of wage rigidities in accounting for labour market fluctuations in the context of the search and matching model. Blanchard and Galí (2007, 2010) emphasize the policy trade-offs generated by the presence of wage rigidities in a New Keynesian model. Zanetti (2007) shows how wage setting by unions can be a source of such wage rigidities. 
for goods. Accordingly, aggregate demand management, rather than wage flexibility, is key to employment stability.

More recently, Galí (2013) revisited Keynes' argument through the lens of a standard New Keynesian model with price and wage stickiness à la Calvo, and in the absence of a zero lower bound (ZLB) constraint on the nominal interest rate. Two results are worth stressing from that analysis. First, the extent to which greater wage flexibility contributes to employment and output gap stability hinges critically on the monetary policy rule in place. More precisely, it is the strength of the central bank's systematic response to inflation that largely determines the response of aggregate demand to changes in wages.

Second, Gali (2013) also shows an increase in wage flexibility tends to raise the volatility of price and wage inflation, both of which are costly because they generate an inefficient allocation of resources in the presence of staggered price and wage setting. Thus, if the central bank follows a policy rule that calls for a relatively weak response to inflation, the benefits of increased wage flexibility in the form of a more stable output gap and employment will generally be small, and likely more than offset by the welfare losses brought about by the more volatile price and wage inflation. However, when the Taylor rule calls for a sufficiently aggressive response to inflation, or when the central bank follows the optimal policy (with commitment), an increase in wage flexibility tends to improve welfare, at least for reasonable calibrations of the economy's parameters.

In the present paper, we extend the analysis in Galí (2013) by taking explicitly into account a ZLB constraint on the nominal interest rate, and study the role of that constraint in determining the welfare effects from greater wage flexibility. The reason for focusing on the interaction between wage flexibility and the ZLB is that the presence of the latter may limit the ability of a central bank to respond to downward pressures on wage and price inflation in the face of a shock triggering such pressures. Our analysis seeks to assess the extent to which the presence of the ZLB constraint may affect the gains (or losses) from an increase in wage flexibility, under alternative monetary policy regimes (Taylor rule vs. optimal policy) and sources of fluctuations (demand vs. technology shocks).

Several findings of interest emerge from our analysis, which we summarize next.

First, we show that a downward adjustment in labour costs (implemented through a wage subsidy) in a recessionary environment with a binding ZLB may (unintentionally) deepen the downturn, due to the implied procyclical response of the real interest rate when the ZLB binds.

Second, we show that the main finding in Galí (2013), namely that under a (realistic) Taylor rule an increase in wage flexibility is welfare reducing, is robust to the presence of the ZLB constraint. Most importantly for our purposes, we show that the ZLB constraint generally amplifies the adverse effects of greater wage flexibility on welfare.

Third, when demand shocks are the source of fluctuations, we show that an increase in wage flexibility is associated with larger welfare losses even when the central bank follows an optimal monetary policy. However, this is not true for technology shocks.

Finally, we show that under a Taylor rule and conditional on either demand or technology shocks, the introduction of the ZLB constraint (i) amplifies the increase in welfare losses from a (local) simultaneous reduction in both price and wage rigidities and (ii) increases the range of those rigidities for which welfare losses are decreasing in the degree of nominal rigidities, relative to the case without ZLB constraint. 
Overall, our findings call into question the presumed gains from using labour cost adjustments as a stabilizing device, especially in the presence of an occasionally binding ZLB constraint.

Our paper proceeds as follows. Section II reviews the related literature. Section III contains a description of our baseline model. Section IV analyses the effects of an exogenous adjustment in labour costs. Section V studies the effect of wage flexibility on macrostability and welfare. Section VI looks at the implications of simultaneous changes in price and wage flexibility. Section VII concludes.

\section{Related literature}

The present paper is related to several branches of the literature. At a more general level, our paper is related to the recent literature that seeks to understand the implications of the ZLB constraint along different dimensions, including the design of optimal monetary policy (e.g. Adam and Billi (2006, 2007), Nakov (2008), Jung, Teranishi and Watanabe (2005)), the role of forward guidance (e.g. Eggertsson and Woodford (2003)), the emergence of multiple steady states (e.g. Benhabib, Schmitt-Grohé and Uribe (2001, 2002), Mertens and Ravn (2014), Benigno and Fornaro (2017)) and the effectiveness of fiscal policy (Eggertsson (2011), Christiano, Eichenbaum and Rebelo (2011), among others). ${ }^{2}$ That theoretical literature has been complemented by attempts to identify and characterize empirically the impact of a binding ZLB during the recent historical episode. See, for example, Swanson and Williams (2014), Aruoba, Cuba-Borda and Schorfheide (2018), Liu et al. (2019) and Debortoli, Galí and Gambetti (2020).

However, our paper is closely connected to a literature that studies the impact of (changes in) nominal rigidities on macroeconomic stability, without reference to the ZLB constraint. In particular, De Long and Summers (1986) have used a model with staggered Taylor contracts to show that an increase in wage flexibility may be destabilizing due to the contractionary impact of falling prices, working through the expected real rate. More recently, a number of papers have addressed similar concerns using a New Keynesian model. Bhattarai, Eggertsson and Schoenle (2018) study the conditions under which an increase in price flexibility may have destabilizing effects on output and employment, without considering the case of a binding ZLB constraint. They show that this will be the case if demand shocks are dominant and interest rates do not respond strongly to inflation; in contrast, when supply shocks prevail, greater price flexibility is destabilizing only if interest rates respond strongly to inflation.

Galí (2013) addresses a similar question with a focus on wage flexibility and its impact on welfare. He shows that an increase in wage flexibility may be welfare reducing if the interest rate is not too responsive to inflation. Galí and Monacelli (2016) revisit the impact of wage flexibility on macro stability and welfare in the context of an open economy, focusing on the role of the exchange rate regime. They show that a strong concern for exchange rate stability or, in the limit, the adoption of a foreign currency or the membership in a large currency union, make it more likely that welfare is reduced in response to greater

\footnotetext{
${ }^{2}$ Erceg and Lindé (2012) study the differences between the constraints on monetary policy imposed by a binding ZLB and those resulting from a credible exchange rate peg. The two are related, but not identical. In particular, a binding ZLB does not, by itself, constitute an anchor for nominal variables, in contrast to an exchange rate peg.
} 
wage flexibility. ${ }^{3}$ The present paper extends that line of research by taking into account the impact of the ZLB constraint.

Several papers have analysed the interaction between price flexibility and the ZLB. Werning (2011) uses a continuous-time version of the New Keynesian model and shows, among other findings, that when monetary policy lacks commitment and the ZLB is binding, the magnitude of the negative output gap and of deflation resulting from an adverse demand shock are exacerbated by price flexibility. Eggertsson and Krugman (2012) argue that an increase in price and/or wage rigidity may help offset the adverse effects of deflationary shocks in an environment with a binding ZLB, in which lower prices tend to reduce aggregate demand by raising real interest rates, as well as the real value of (nominal) debt, with the consequent drop in spending by debtors. They refer to that stabilizing property of price rigidities as the 'paradox of flexibility'. ${ }^{4}$ Roulleau-Pasdeloup and Zhutova (2018) use an estimated DSGE model representing the US economy during the Great Depression, and conclude that the Hoover 'high wage' policies helped limit the damage from the adverse negative demand shock and succeeded in delaying the liquidity trap episode. Finally, Coibion, Gorodnichenko and Wieland (2012) show that the introduction of downward nominal wage rigidities in a calibrated DSGE model reduces the incidence of ZLB episodes, implying a lower optimal inflation rate. Relative to the previous works, our paper provides an explicit welfare theoretic analysis of the effects of wage rigidities in the presence of an occasionally binding ZLB constraint.

We next turn to a description of our baseline model.

\section{Our baseline model}

We carry out our analysis using a version of the New Keynesian model with staggered price and wage setting à la Calvo, originally developed by Erceg, Henderson and Levin (2000), augmented with a ZLB constraint on the short-term nominal interest rate. In some of the scenarios considered, monetary policy is described by a (truncated) Taylor rule, while in others the central bank is assumed to follow the optimal policy under commitment. We rely on a standard calibration of the model as a baseline for our analysis. Next we introduce briefly the key equations describing the model's equilibrium. The reader can find detailed derivations of those equations as well as a complete analysis of the model in the absence of the ZLB constraint in Galí (2015). ${ }^{5}$

\section{Private sector}

The behaviour of the private sector is described by the equilibrium conditions introduced in this section, which correspond to a closed economy version of the New Keynesian model

\footnotetext{
${ }^{3}$ Related, Eggertsson, Ferrero and Raffo (2014) raise a warning on the possible contractionary effects of structural reforms (modelled as favourable supply shocks) in an economy that is part of a larger currency union, due to the increase in real interest rates resulting from the combination of deflationary pressures and an unresponsive nominal rate.

${ }^{4}$ Eggertsson (2010) provided an early conjecture of that result, focusing exclusively on the expected inflation channel.

${ }^{5}$ For convenience, we use an identical notation to Galí (2015). The only difference with that model lies in the introduction of a wage subsidy. See Galí and Monacelli (2016) for details.
} 
with staggered price and wage setting, without capital accumulation or a fiscal sector. All the equations are log-linearized around a steady state with zero price and wage inflation. A wage subsidy is assumed, financed through lump-sum taxes. The size of that wage subsidy in the steady state exactly offsets the distortions resulting from price and wage markups. Derivations can be found in Galí (2015), chapter 6).

The supply side of the economy is described by the following three equations representing the dynamics of price and wage inflation, $\pi_{t}^{p}$ and $\pi_{t}^{w}$

$$
\begin{gathered}
\pi_{t}^{p}=\beta E_{t}\left\{\pi_{t+1}^{p}\right\}+\varkappa_{p} \tilde{y}_{t}+\lambda_{p} \tilde{\omega}_{t} \\
\pi_{t}^{w}=\beta E_{t}\left\{\pi_{t+1}^{w}\right\}+\varkappa_{w} \tilde{y}_{t}-\lambda_{w} \tilde{\omega}_{t} \\
\tilde{\omega}_{t} \equiv \tilde{\omega}_{t-1}+\pi_{t}^{w}-\pi_{t}^{p}-\Delta \omega_{t}^{n}
\end{gathered}
$$

where $\tilde{y}_{t} \equiv y_{t}-y_{t}^{n}$ and $\tilde{\omega}_{t} \equiv \omega_{t}-\omega_{t}^{n}$ denote, respectively, the output and wage gaps, with $y_{t}^{n}$ and $\omega_{t}^{n}$ representing the (log) natural output and $(\log )$ natural wage (i.e. their corresponding equilibrium values in the absence of nominal rigidities). In addition, we note that $\varkappa_{p} \equiv \frac{\alpha \lambda_{p}}{1-\alpha}, \varkappa_{w} \equiv \lambda_{w}\left(\sigma+\frac{\varphi}{1-\alpha}\right), \lambda_{p} \equiv \frac{\left(1-\theta_{p}\right)\left(1-\beta \theta_{p}\right)}{\theta_{p}} \frac{1-\alpha}{1-\alpha+\alpha \epsilon_{p}}$, and $\lambda_{w} \equiv \frac{\left(1-\theta_{w}\right)\left(1-\beta \theta_{w}\right)}{\theta_{w}\left(1+\epsilon_{w} \varphi\right)}$, where $\theta_{p} \in[0,1)$ and $\theta_{w} \in[0,1)$ are the Calvo indexes of price and wage rigidities, while $\epsilon_{p}>1$ and $\epsilon_{w}>1$ denote the elasticities of substitution among varieties of goods and labour services respectively. Parameters $\sigma, \varphi$ and $\beta$ denote the household's coefficient of relative risk aversion, the curvature of labour disutility and the discount factor respectively. Parameter $\alpha$ denotes the degree of decreasing returns to labour in production. As shown in Galí (2015), equations (1) and (2) can be derived from the aggregation of price and wage setting decisions of workers and firms, in an environment in which such re-optimization takes place with probabilities $1-\theta_{p}$ and $1-\theta_{w}$ respectively. Much of the focus of our analysis below is on the consequences of changes in the wage rigidity parameter $\theta_{w}$.

The natural output and wage are given by (ignoring constant terms):

$$
\begin{aligned}
& y_{t}^{n}=\psi_{y a} a_{t}+\psi_{y \tau} \tau_{t} \\
& \omega_{t}^{n} \equiv \psi_{\omega a} a_{t}+\psi_{\omega \tau} \tau_{t}
\end{aligned}
$$

where $a_{t}$ is an exogenous technology shifter which follows an exogenous $A R(1)$ process with autoregressive coefficient $\rho_{a}$. Variable $\tau_{t}$ denotes a proportional wage subsidy that subtracts from the labour cost incurred by firms. ${ }^{6}$ It can be shown that $\psi_{y a} \equiv \frac{1+\varphi}{\sigma(1-\alpha)+\varphi+\alpha}$, $\psi_{y \tau} \equiv \frac{1-\alpha}{\sigma(1-\alpha)+\varphi+\alpha}, \psi_{\omega a} \equiv \frac{\sigma+\varphi}{\sigma(1-\alpha)+\varphi+\alpha}$ and $\psi_{\omega \tau} \equiv \frac{\sigma(1-\alpha)+\varphi}{\sigma(1-\alpha)+\varphi+\alpha}$.

\footnotetext{
${ }^{6}$ More specifically, we assume that the effective wage per hour of work paid by the firm is given by $\left(1-\tau_{t}\right) W_{t}$, which we approximate in $\operatorname{logs}$ as $w_{t}-\tau_{t}$ with $w_{t} \equiv \log W_{t}$ and $\tau_{t}$ is taken to be 'small'. Total wage subsidy expenses are financed with a lump-sum tax.
} 
The demand side of the economy is described by a dynamic IS equation:

$$
\tilde{y}_{t}=E_{t}\left\{\tilde{y}_{t+1}\right\}-\frac{1}{\sigma}\left(i_{t}-E_{t}\left\{\pi_{t+1}^{p}\right\}-r_{t}^{n}\right)
$$

where $i_{t}$ is the nominal interest rate, and $r_{t}^{n}$ is the natural rate of interest. Under our assumptions, the latter is given by $r_{t}^{n}=\rho+\left(1-\rho_{z}\right) z_{t}+\sigma E_{t}\left\{\Delta y_{t+1}^{n}\right\}$, where $\rho \equiv-\log \beta$ is the discount rate and $z_{t}$ is a discount factor shifter (which we refer to as 'demand' shock) which follows an exogenous $A R(1)$ process with autoregressive coefficient $\rho_{z}$. Note that in the absence of nominal rigidities, demand shocks have no effect on output or employment, only on the real interest rate. ${ }^{7}$

\section{Monetary policy}

In our analysis we consider two alternative monetary policy regimes. The first regime is described by a 'truncated' Taylor rule given by:

$$
i_{t}=\max \left[0, i_{t}^{*}\right]
$$

where

$$
i_{t}^{*}=\phi_{i} i_{t-1}^{*}+\left(1-\phi_{i}\right)\left(\rho+\phi_{p} \pi_{t}^{p}+\phi_{y} \tilde{y}_{t}\right) .
$$

The previous rule, which incorporates explicitly a ZLB constraint, can be viewed as capturing in a parsimonious way the behaviour of central banks in many advanced economies. Note that $i_{t}^{*}$ can be interpreted as a shadow interest rate in that context. ${ }^{8}$ Hence, equations (1) through (6) describe the equilibrium under the Taylor rule.

The second regime we consider corresponds to the optimal policy under commitment and subject to a ZLB constraint. That policy is a state contingent plan that maximizes the representative household's welfare, subject to a sequence of private sector constraints given by equations (1) through (4), and the ZLB constraint, $i_{t} \geqslant 0$, all for $t=0,1,2, \ldots$ That optimal policy problem is described formally in the Appendix and gives rise to a set of difference equations which, together with equations (1) through (4), describe the equilibrium under the optimal policy with commitment.

\footnotetext{
${ }^{7}$ In the absence of nominal rigidities, the demand shock bares no effect on output or employment. The reason has to do with the particular way in which it is introduced in the model, namely as a shock to the discount factor, which changes in the same proportion the marginal disutility of labour and the marginal utility of consumption. As a result, labour supply does not change. Labour demand does not change either, so employment and output do not change, they are fully pinned down by the supply block of the model. Only the real rate adjusts in order to keep consumption unchanged. With nominal rigidities, there is no longer a simple mapping between the real wage and employment (because the markup is variable). Instead employment and output are determined by the aggregate demand for goods, which changes in response to the discount factor shock, as long as monetary policy does not offset it fully. See chapters 2 and 3 in Galí (2015) for details.

${ }^{8}$ Our specification of the rule for the shadow rate $i_{t}^{*}$, which makes the latter a function of its own lag (as opposed to the lag of the actual policy rate $i_{t}$ ) implies a kind of 'forward guidance' that dampens the extent of the economy's collapse (and its perverse feedback effects) during ZLB episodes. The previous feature is also needed to prevent the economy from 'blowing up' when we reduce nominal rigidities in the scenarios considered. Simulations of the model with values of $\phi_{i}$ equal or close to zero generally crashed when wage and/or price rigidities were sufficiently low. This is never the case under our baseline setting $\phi_{i}=0.8$.
} 
TABLE 1

Baseline calibration

\begin{tabular}{lll}
\hline Parameter & Description & Value \\
\hline$\beta$ & Discount factor & 0.995 \\
$\sigma$ & Curvature of consumption utility & 1 \\
$\varphi$ & Curvature of labour disutility & 5 \\
$\alpha$ & Index of decreasing returns to labour & 0.25 \\
$\epsilon_{p}$ & Elasticity of substitution of goods & 9 \\
$\epsilon_{w}$ & Elasticity of substitution of labour & 4.5 \\
$\theta_{p}$ & Calvo index of price rigidities & 0.75 \\
$\theta_{w}$ & Calvo index of wage rigidities & 0.75 \\
$\phi_{i}$ & Smoothing coefficient in the Taylor rule & 0.8 \\
$\phi_{p}$ & Rule coefficient on price inflation & 1.5 \\
$\phi_{y}$ & Rule coefficient on output gap & 0.125 \\
$\rho_{a z}$ & Persistence of shocks & 0.8 \\
$\sigma_{a}$ & Std. deviation of technology shock & 0.033 \\
$\sigma_{z}$ & Std. deviation of demand shock & 0.044 \\
\hline
\end{tabular}

Notes: Values are shown in quarterly rates.

\section{Baseline calibration}

Our baseline calibration is quite conventional and largely follows Galí (2015). We set the discount factor $\beta$ to 0.995 , implying a (annualized) steady-state real interest rate of $2 \%$. We set $\sigma=1, \varphi=5$ and $\alpha=0.25$. Elasticity of substitution parameters $\epsilon_{p}$ and $\epsilon_{w}$ are set to 9 and 4.5 , respectively, implying a steady-state subsidy $\tau=0.31 .{ }^{9}$ We set $\theta_{p}=$ $\theta_{w}=0.75$, consistent with an average duration of price and wage spells of one year. We adopt the interest rate rule coefficients proposed in Taylor (1993), that is, $\phi_{p}=1.5$ and $\phi_{y}=0.125$. The smoothing coefficient in the Taylor rule is set to 0.8 , close to the estimates in Clarida, Galí and Gertler (2000) and others. The autoregressive coefficient of the driving variables is set to 0.8 to generate sufficient persistence, while the standard deviation of their respective innovation is chosen in order to have a ZLB incidence of 5\% under the Taylor rule, and conditional on each of the shocks (demand or technology) being the only source of fluctuations in the economy. Our baseline calibration is summarized in Table 1.

Next we turn to the analysis of some of the model's predictions regarding the interaction of wage flexibility and the ZLB. ${ }^{10}$ We start by studying the impact of the latter on the effectiveness of labour cost reductions.

\footnotetext{
${ }^{9}$ The optimal steady-state subsidy satisfies $(1-\tau) \frac{\epsilon_{P}}{\epsilon_{P}-1} \frac{\epsilon_{w}}{\epsilon_{w}-1}=1$. See chapter 6 in Galí (2015) for details.

${ }^{10}$ The model outcomes are obtained with Dynare (https://www.dynare.org). Specifically, we feed the equilibrium conditions of the model into Dynare. Then, in order to obtain the dynamic responses in Figures 1 and 2, we use the perfect foresight, deterministic simulations algorithm implemented in Dynare with the 'simul' command. However, to generate the simulated equilibrium paths needed to construct Figures 3-10 (as well as Figures A1-A3 in the online appendix), we employ the stochastic simulations algorithm (assuming agents believe there will be no more shocks in the following periods) implemented in Dynare with the 'extended_path' command. Replication files are available from the authors upon request.
} 


\section{The effects of labour cost reductions facing the zero lower bound}

The eventual stabilizing role of wage flexibility hinges critically on the influence that adjustments in wages (or other components of labour costs) may have on output and employment.

As argued in Gali (2013), in an economy described by the New Keynesian model, the amount of labour hired is determined, in the short run and for a given technology, not by the prevailing wage but by the quantity of output that firms want to produce which, in turn, is determined by aggregate demand. Thus, the effect of a change in labour costs on employment is transmitted through the impact of the former on marginal costs, inflation and - through the monetary policy rule - on nominal and real interest rates, which finally affect consumption. If the ZLB is binding and, as a result, the change in inflation does not elicit a change in the nominal rate, the previous causal chain in the transmission of labour cost adjustments to employment breaks down. Furthermore, in the face of a constant nominal rate, any reduction in expected inflation caused by a downward adjustment in labour costs will lead to a rise in the real interest rate, and thus may end up having a 'perverse' effect on output and employment.

In order to illustrate the role played by the ZLB in determining the effects of labour cost adjustments, we use the model above to analyse the impact of a large, unanticipated, negative demand shock, to which the government responds with a wage subsidy increase. The latter is presumably enacted in order to counteract the adverse effects of the shock on output and employment. The adverse demand shock is assumed to last for 20 quarters, and its (constant) size is normalized so that the drop of output on impact is $4 \%$ when in the presence of a ZLB constraint and the absence of a change in the wage subsidy.

Figure 1 displays the responses of output, inflation, and the nominal and real interest rates to the demand shock just described and a simultaneous wage subsidy increase, in the absence of a ZLB constraint. We assume that the increase in the wage subsidy lasts for as long as the shock (i.e. 20 quarters) and has an alternative size of $0 \%, 1 \%$ and $3 \%$, corresponding respectively to the lines with (black) squares, (blue) circles and (red) diamonds. As Figure 1 makes clear, in the no ZLB environment, the effects of the wage subsidy accord to conventional wisdom: the larger the subsidy increase, the more it stabilizes output in the face of the adverse demand shock. The reason is that a larger subsidy triggers a larger decrease in inflation and hence a stronger monetary policy response in the form of lower nominal and real interest rates, as captured in the bottom panels.

As shown in Figure 2, however, things are considerably different in the presence of the ZLB constraint. Note that the size of the demand shock is large enough to make the ZLB binding for many periods, independently of the response of the wage subsidy. The latter, however, has a significant impact on the response of output and inflation. Thus, we see that the larger the increase in the wage subsidy, the weaker is its stabilizing effect (i.e. the deeper the short run decline in output in response to the adverse demand shock).

In particular, the fourth panel of Figure 2 displays the response of the real interest rate under the three alternative sizes of the wage subsidy, and points to the mechanism responsible for the 'counterproductive' impact of a larger wage subsidy: the deflationary effects of the latter combined with a binding ZLB lead to a higher real rate, thus amplifying the initial negative effects of the shock on aggregate demand and output. 

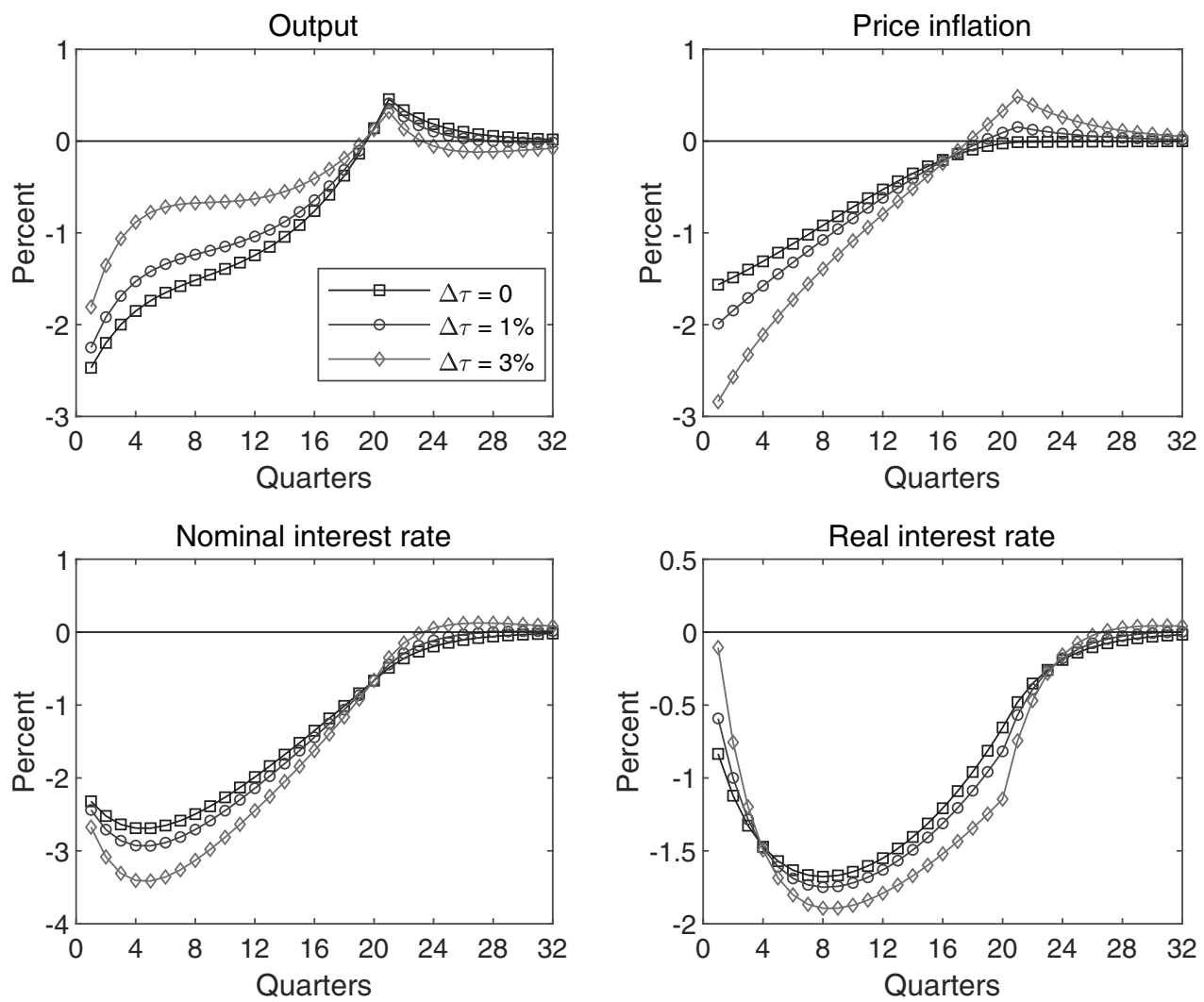

Figure 1. Dynamic responses to a wage subsidy if zero lower bound absent

The previous exercise provides an illustration of the potentially perverse effects that large downward adjustments in labour costs may have in combination with a binding ZLB constraint. Needless to say, actual economies are not always facing a binding ZLB. In the remainder of the paper we keep the wage subsidy unchanged, and instead we look at the differential response of the economy to adverse shocks under alternative degrees of wage rigidities. To the extent that ZLB episodes are recurrent, the associated recessions may be deeper and more persistent if they bring about large downward wage adjustments, which will generally be the case if wages are more flexible. In that case, the presence of the ZLB may reduce or even reverse the sign of the welfare gains that the conventional wisdom associates with greater wage flexibility. The analysis below seeks to evaluate the plausibility of that hypothesis.

\section{Wage rigidities, welfare and the zero lower bound}

A key objective of our analysis is the evaluation of the impact of changes in the degree of wage rigidity on welfare in the presence of a ZLB constraint. For that purpose, we use as a welfare metric the second-order approximation to the average welfare losses experienced by the representative household as a result of fluctuations around an efficient, zero inflation 

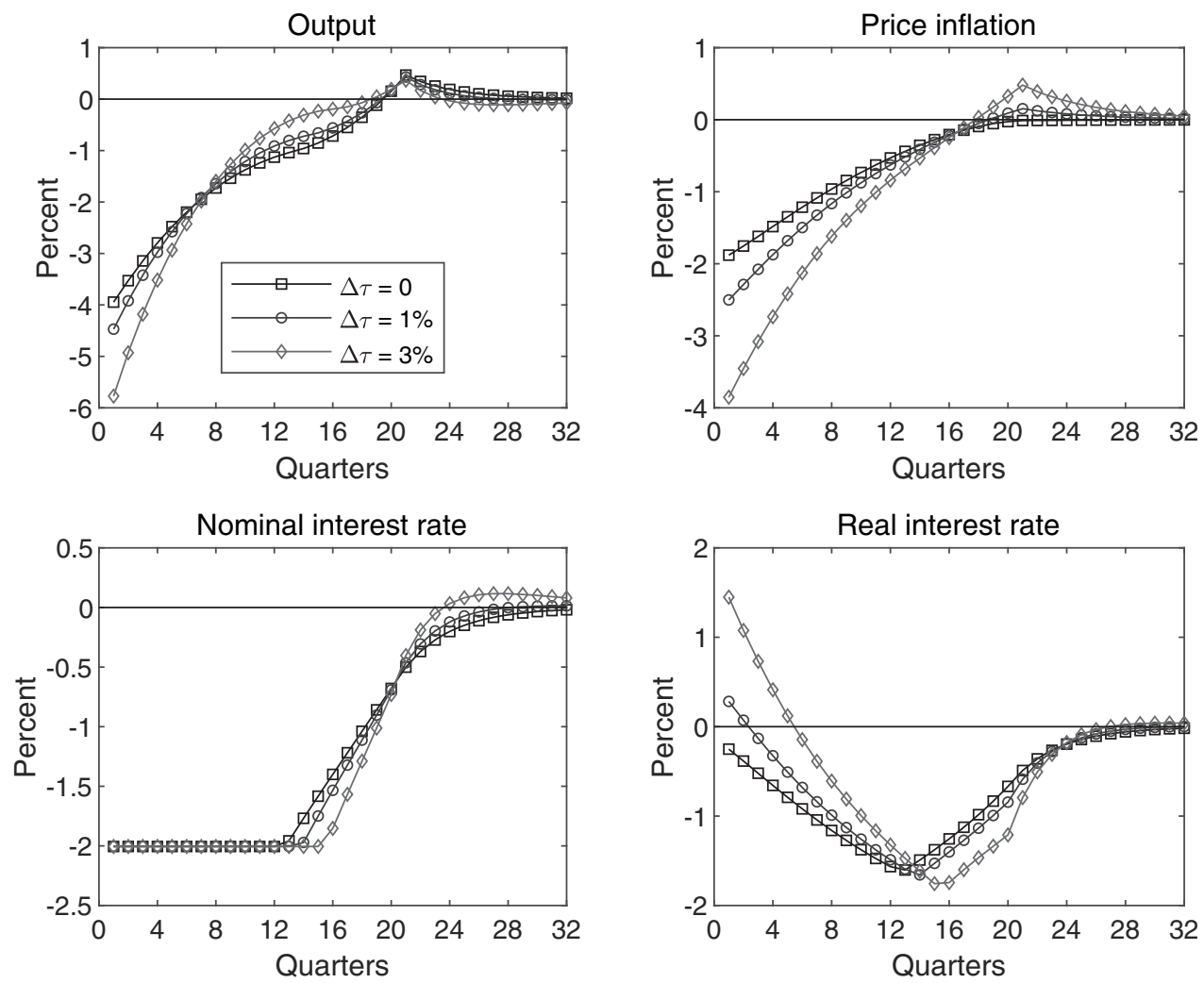

Figure 2. Dynamic responses to a wage subsidy during a zero lower bound episode

steady state, expressed as a fraction of steady state consumption. Such a welfare metric can be written as: ${ }^{11}$

$$
\mathbb{L}=\frac{1}{2}\left[\left(\sigma+\frac{\varphi+\alpha}{1-\alpha}\right) \operatorname{var}\left(\tilde{y}_{t}\right)+\frac{\epsilon_{p}}{\lambda_{p}} \operatorname{var}\left(\pi_{t}^{p}\right)+\frac{\epsilon_{w}(1-\alpha)}{\lambda_{w}} \operatorname{var}\left(\pi_{t}^{w}\right)\right]
$$

Note that the welfare loss has three distinct components, associated with the volatilities in the output gap, price inflation and wage inflation. Parameter $\theta_{w}$ enters the welfare loss function through $\lambda_{w}$, to which it is inversely related. Thus, an increase in wage flexibility (i.e. a smaller $\theta_{w}$ ) reduces welfare losses, for any given volatility of wage inflation. The reason is that, given $\operatorname{var}\left(\pi_{t}^{w}\right)$, more flexible wages are associated with less wage dispersion, and a smaller inefficiency resulting from misallocation of labour. In equilibrium, however, the volatility of wage inflation, price inflation and the output gap is not invariant to a change in $\theta_{w}$. In particular, we expect that greater wage flexibility will be associated with higher volatility of wage inflation and, ceteris paribus, of price inflation as well. On the other hand, more flexible wages should make employment (and, thus, output) deviate less from their natural counterparts, thereby reducing $\operatorname{var}\left(\tilde{y}_{t}\right)$. As a result, the net effect on welfare from a reduction in $\theta_{w}$ is generally ambiguous ex ante. As emphasized in Galí (2013) (and Galí

\footnotetext{
${ }^{11}$ See chapter 6 in Galí (2015) for a derivation.
} 

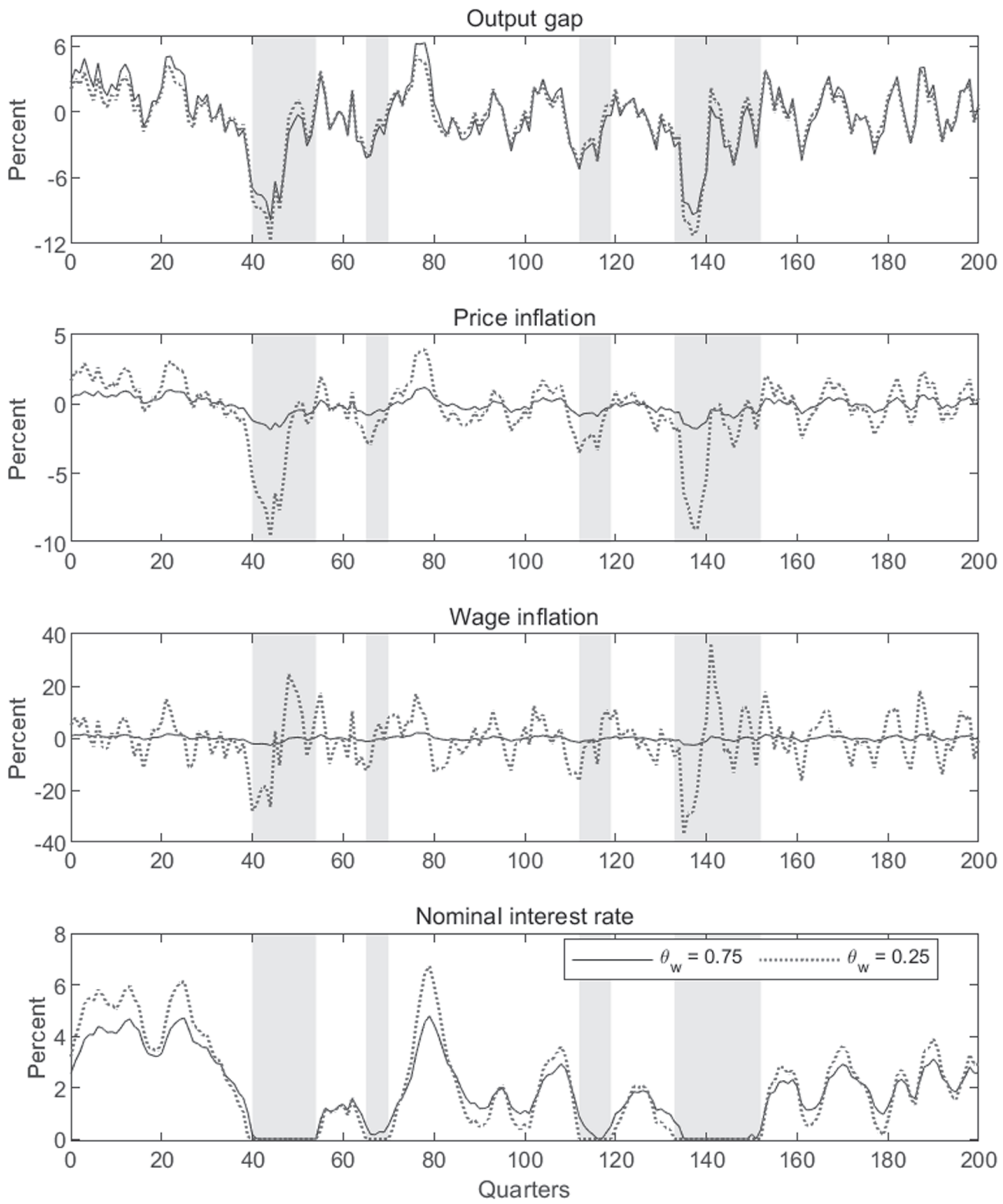

Figure 3. Paths conditional on demand shocks: effect of wage rigidities

and Monacelli (2016) in the context of a small open economy), which welfare component ends up dominating depends to a large extent on the monetary policy regime in place. The latter is, in turn, affected by the presence of a ZLB constraint. Next we describe such effects through a number of simulations.

Figure 3 displays artificial time series for the output gap, price inflation, wage inflation and the nominal rate, generated by the equilibrium of our calibrated model, with the ZLB constraint and demand shocks as the source of fluctuations. The two lines correspond to alternative assumptions on the degree of wage rigidity: our baseline assumption $\left(\theta_{w}=0.75\right.$; 

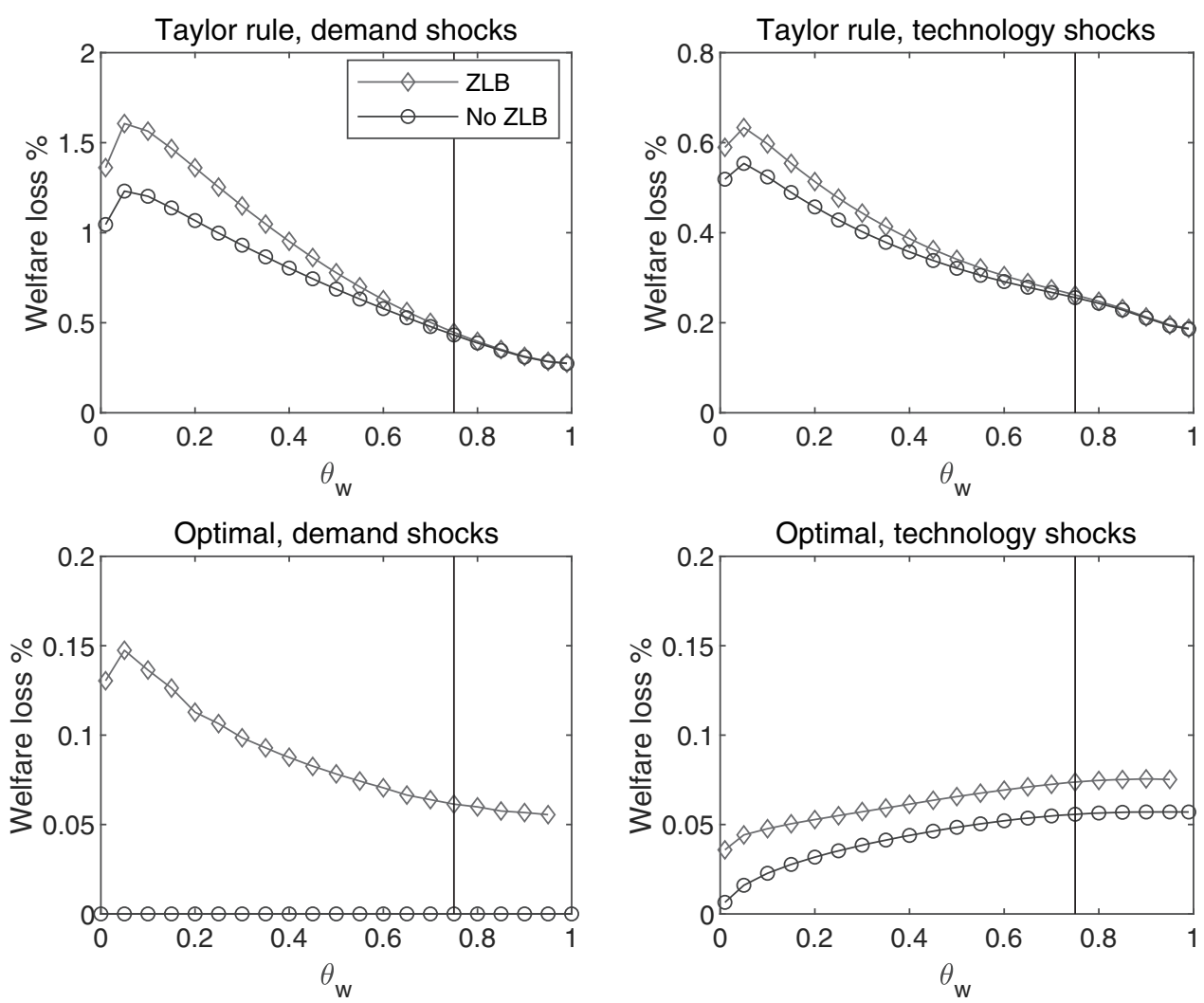

Figure 4. Wage rigidities and welfare: effect of zero lower bound

in solid blue) and an alternative with more flexible wages $\left(\theta_{w}=0.25\right.$; in dotted red). The shaded areas highlight the periods during which the ZLB is binding. The simulations reported in the figure allow us to illustrate visually some of the findings discussed below in more detail. As is clear from the top panel, an increase in wage flexibility has only a small effect on output gap volatility: the two lines almost lie on top of each other. This contrasts with the behaviour of price and wage inflation, whose volatility is much larger when wages are more flexible. A closer look at the figure suggests that it is precisely during episodes when the ZLB is binding that the gap in the volatility between the two series is particularly large.

Figure 4 shows the welfare losses as a function of the index of nominal wage rigidities, $\theta_{w}$, with the latter's baseline value (0.75) indicated by a vertical line. ${ }^{12}$ Each of the four panels corresponds to a particular combination of monetary policy regime (Taylor rule vs. optimal policy) and source of fluctuations (demand vs. technology shocks), and displays the welfare losses with and without a ZLB constraint as lines with red diamonds and blue

\footnotetext{
${ }^{12}$ We generate simulated equilibrium paths of 10.000 periods for each parameter configuration considered. This long simulation is used to compute the variances of price inflation, wage inflation and the output gap that are needed to determine the welfare losses associated with each parameter configuration. Note that the duration of the ZLB is not normalized for different values of $\theta_{w}$. Rather, the shock volatility is chosen so that under the baseline calibration the economy is at the ZLB 5\% of the time. When we change $\theta_{w}$ the ZLB frequency and duration change endogenously.
} 
circles respectively. Not surprisingly, welfare losses appear to be generally larger with the ZLB constraint, which bring about greater instability. But this is not the focus of our inquiry, which pertains instead to the effect of changes in $\theta_{w}$ on welfare, that is, on the slope of the welfare loss function, rather than on its relative position.

Our results for the case of no ZLB, represented by the lines with blue circles in Figure 4, replicate the main qualitative findings in Gali (2013). First, and under the calibrated Taylor rule, an increase in wage flexibility (i.e. a decrease in $\theta_{w}$ ) leads to higher welfare losses for a large range of initial $\theta_{w}$ values (one that includes the baseline setting of 0.75). This is true for both technology and demand shocks. Under the optimal policy, however, welfare losses are either zero independently of wage rigidity (in the case of demand shocks, which are fully offset by the central bank), or they are decreasing as wages become more flexible (in the case of technology shocks). ${ }^{13}$ The previous simulations thus make clear that the existence of welfare gains from greater wage flexibility is not generally true. On the contrary, the sign and extent of the resulting welfare effects depend critically on the monetary policy in place (and the nature of the shock in the case of the optimal policy).

The introduction of a ZLB constraint alters those findings in two ways, as a comparison of the two lines in each panel makes clear. First, under the Taylor rule, the presence of the ZLB amplifies the adverse effects of greater wage flexibility on welfare, both for demand and technology shocks, as reflected in a steeper welfare loss function for a broad range of $\theta_{w}$ values (including the baseline one). Second, under the optimal policy and demand shocks, an increase in wage flexibility raises welfare losses when the ZLB constraint is present, for a very large range of initial $\theta_{w}$ values. Under technology shocks, however, the introduction of the ZLB raises welfare losses, without affecting significantly the sensitivity of welfare to wage rigidity (although the gains from greater wage flexibility appear to be slightly smaller in the ZLB case).

Next we show that the finding that the presence of a ZLB amplifies the adverse welfare effects of greater wage flexibility is robust to alternative model calibrations. Figure 5 shows the ratio of welfare losses with and without the ZLB constraint, as a function of $\theta_{w}$, and for alternative values of another parameter (a different parameter for each graph). For concreteness, the figure assumes demand shocks as the source of fluctuations. The top four panels examine the impact of different settings for the Taylor rule parameters $\left(\phi_{p}, \phi_{y}, \phi_{i}\right.$, $\rho$ ). Several results are worth pointing out. First, we see that the loss ratio is larger than 1 in all cases, that is, the introduction of the ZLB constraint always reduces welfare for any given calibration. Second, we see that in response to greater wage flexibility (i.e. a reduction in $\theta_{w}$ ), welfare losses increase in a greater proportion when the ZLB constraint is present, as reflected by the negative slope of the loss ratio curves. That impact of the ZLB on the welfare effect of greater wage flexibility holds for all the rule coefficients considered, but is particularly strong for large values of $\phi_{p}$ and $\phi_{y}$, and small values of $\phi_{i}$ and $\rho$, because in all of those cases the incidence of a binding ZLB is higher.

\footnotetext{
${ }^{13}$ As discussed in Galí (2013), the finding that welfare losses are an inverse monotonic function of wage rigidity under the optimal policy is not completely general and may be overturned for some extreme calibrations (e.g. extreme price stickiness).
} 

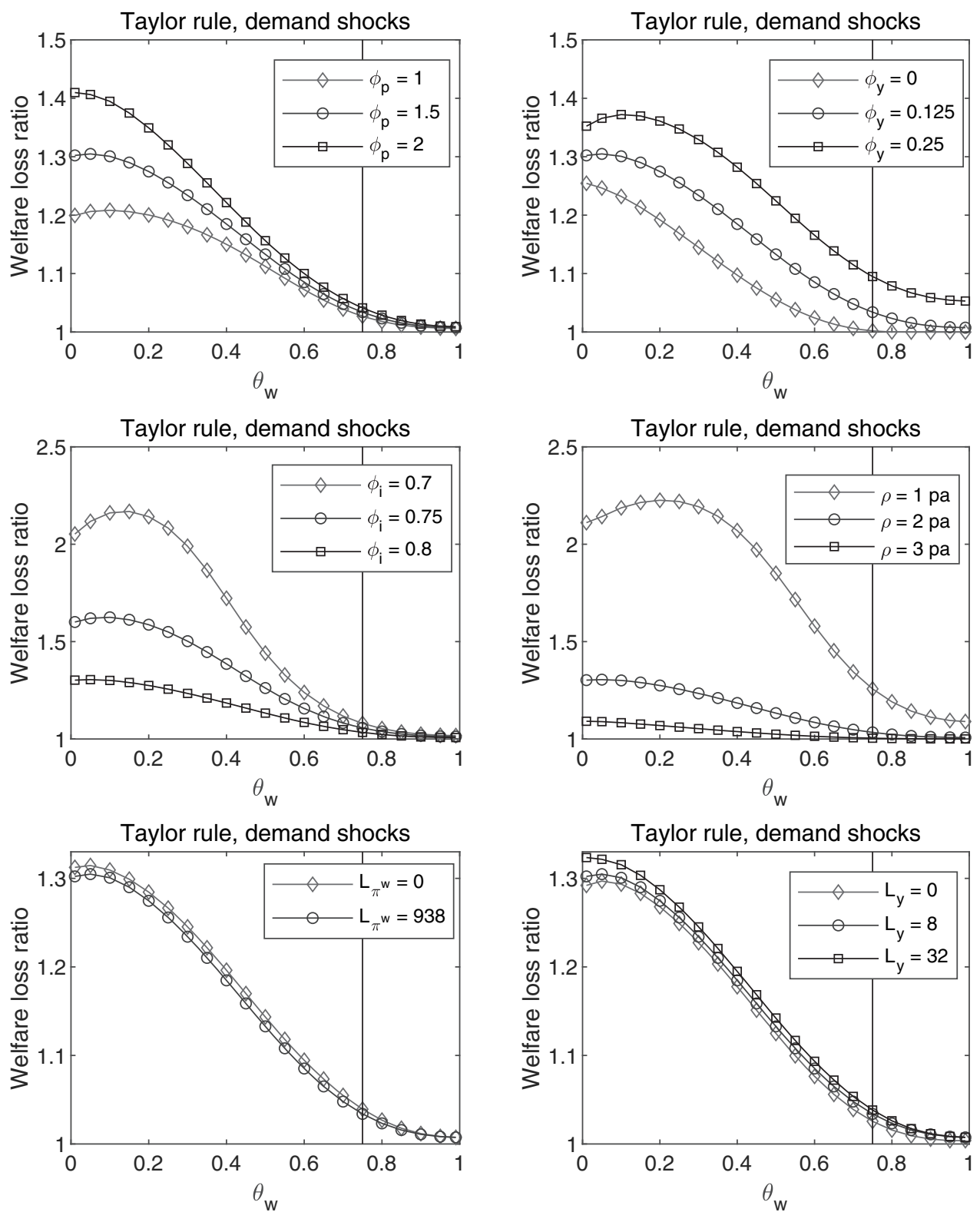

Figure 5. Wage rigidities and welfare loss from zero lower bound: robustness to parameter changes

The two bottom panels of Figure 5 examine the robustness of the main findings to alternative calibrations of the weights in the welfare loss function. ${ }^{14}$ In particular, the bottom-left panel compares the ratio of welfare losses under the weights implied by our baseline calibration, with that from a specification of welfare losses that assign a zero weight to wage inflation fluctuations, possibly in accordance to central bank's conventional focus

\footnotetext{
${ }^{14}$ The baseline calibration implies the weights in the welfare loss function are $L_{y}=\sigma+\frac{\varphi+\alpha}{1-\alpha}=8, L_{\pi^{p}}=\frac{\epsilon_{p}}{\lambda_{p}}=426$ and $L_{\pi^{w}}=\frac{\epsilon_{w}(1-\alpha)}{\lambda_{w}}=938$.
} 

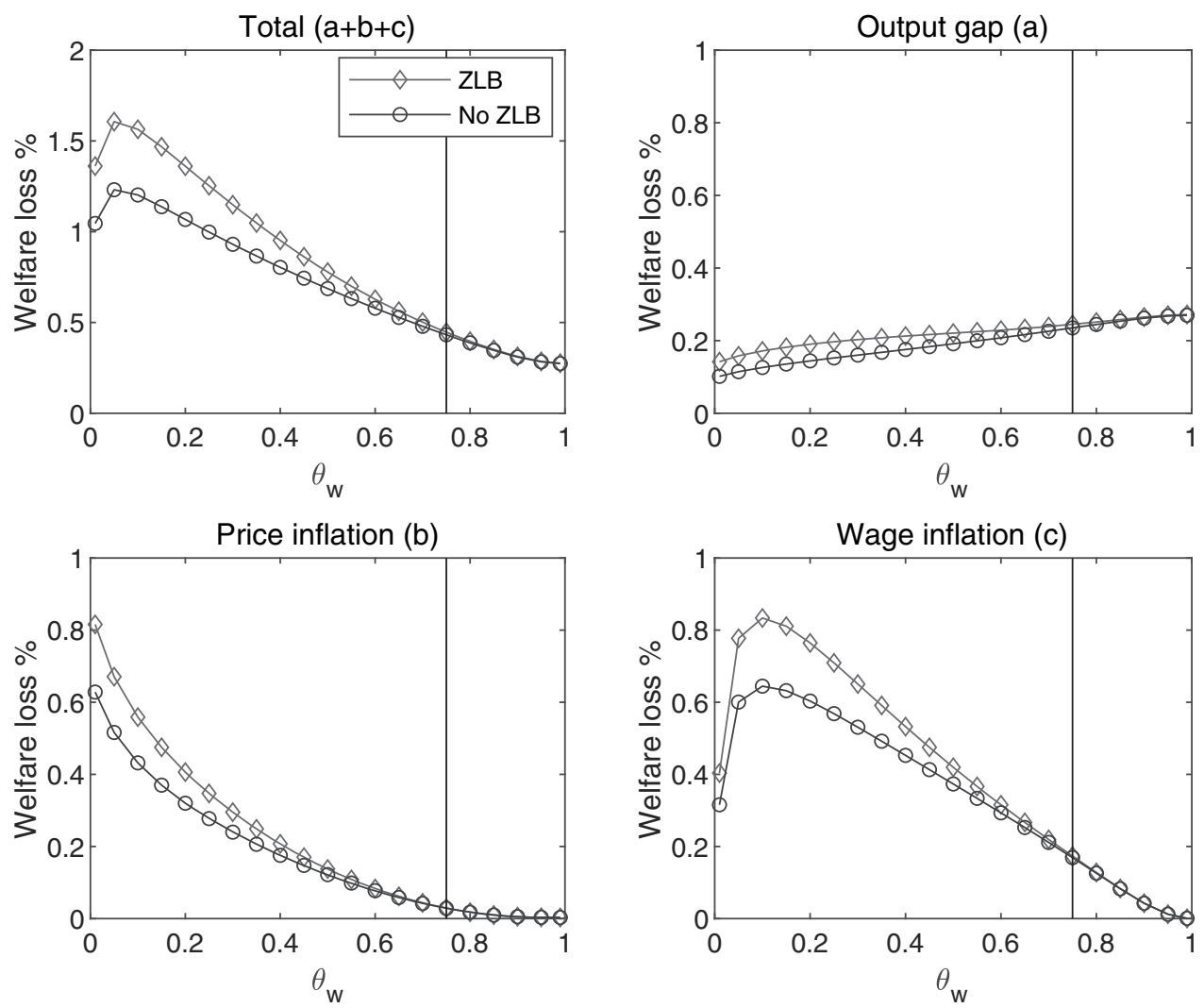

Figure 6. Wage rigidities and welfare components: Taylor rule and demand shocks

on output gap and price inflation stabilization. The bottom-right panel instead considers two settings for the weight of output gap volatility different from the one implied by our baseline calibration. It is clear from these two panels that our main finding regarding the impact of the ZLB on the welfare effects of changes in wage flexibility is also robust to those changes in the weights of the loss function.

Similar findings to those in Figure 5 are obtained when technology shocks are the source of fluctuations (see Figure A1 in the online appendix).

We show next how the presence of the ZLB constraint affects the three components of the welfare loss function, associated respectively with the volatility of the output gap, price inflation and wage inflation. Figure 6 shows the welfare loss and its components under a Taylor rule with demand shocks as the source of fluctuations, with and without the ZLB constraint. On the absence of the ZLB, an increase in wage flexibility (starting from its baseline value) stabilizes the output gap (which reduces welfare losses), but, however, increases the volatility in price and wage inflation (which increases welfare losses). The latter effect appears to dominate, except when the initial degree of wage rigidities is very low. Note in particular that the (local) increase in the losses from a higher volatility of wage inflation occurs despite the fact that the cost of any given level of such volatility 

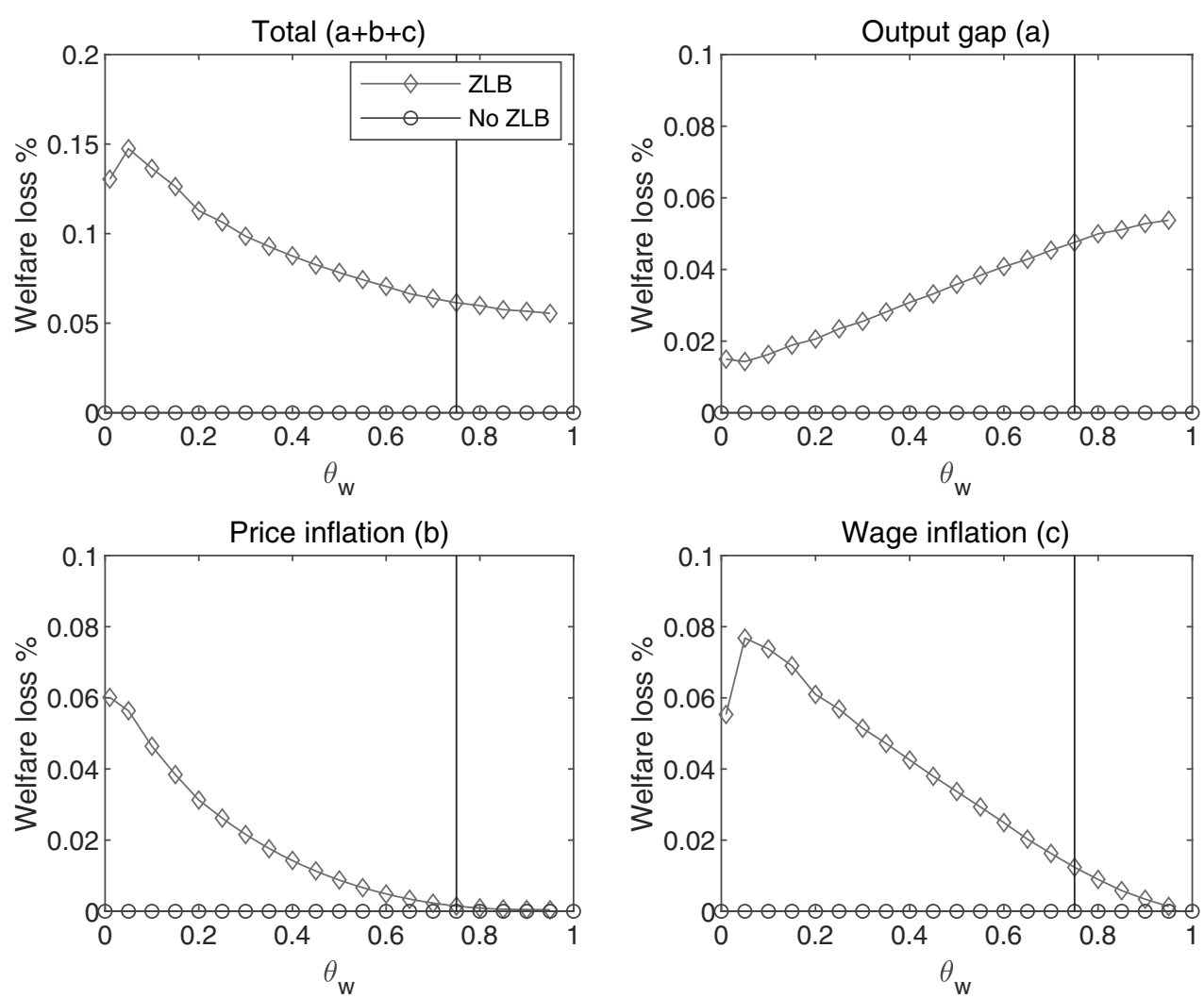

Figure 7. Wage rigidities and welfare components: optimal policy and demand shocks

is smaller when wages are more flexible. ${ }^{15}$ The presence of the ZLB constraint raises the volatility in the output gap, price inflation and wage inflation for any given level of $\theta_{w}$, thereby raising the corresponding welfare loss components. More interestingly, we see that the three components play a role in the amplification of the adverse welfare effects of greater wage flexibility that results from the presence of the ZLB constraint. Similar findings are obtained when technology shocks are the source of fluctuations although with lower magnitudes of amplification (see Figure A2 in the online appendix).

Figure 7 shows the welfare loss function and its components under the optimal policy with commitment, with and without the ZLB, when demand shocks are the source of fluctuations. As discussed above, when ZLB is absent, the optimal policy fully stabilizes the output gap, price inflation and wage inflation, so no losses emerge from any of those components, as captured by the flat lines at zero. The presence of the ZLB makes it impossible for monetary policy to fully offset large adverse demand shocks. As a result, the output gap, price and wage inflation deviate from their first-best values and welfare losses arise. An

\footnotetext{
${ }^{15}$ In the figure, there is a non-monotonic effect of wage flexibility on the component of welfare associated with volatility in wage inflation (bottom-right panel). The reason for this non-monotonicity is that, as explained earlier, if wages become more flexible, the volatility in wage inflation increases; however, the weight attached to such volatility in the social welfare function decreases. Thus, if wages are very flexible, a further increase in wage flexibility leads to a reduction in the welfare loss associated with wage inflation volatility.
} 

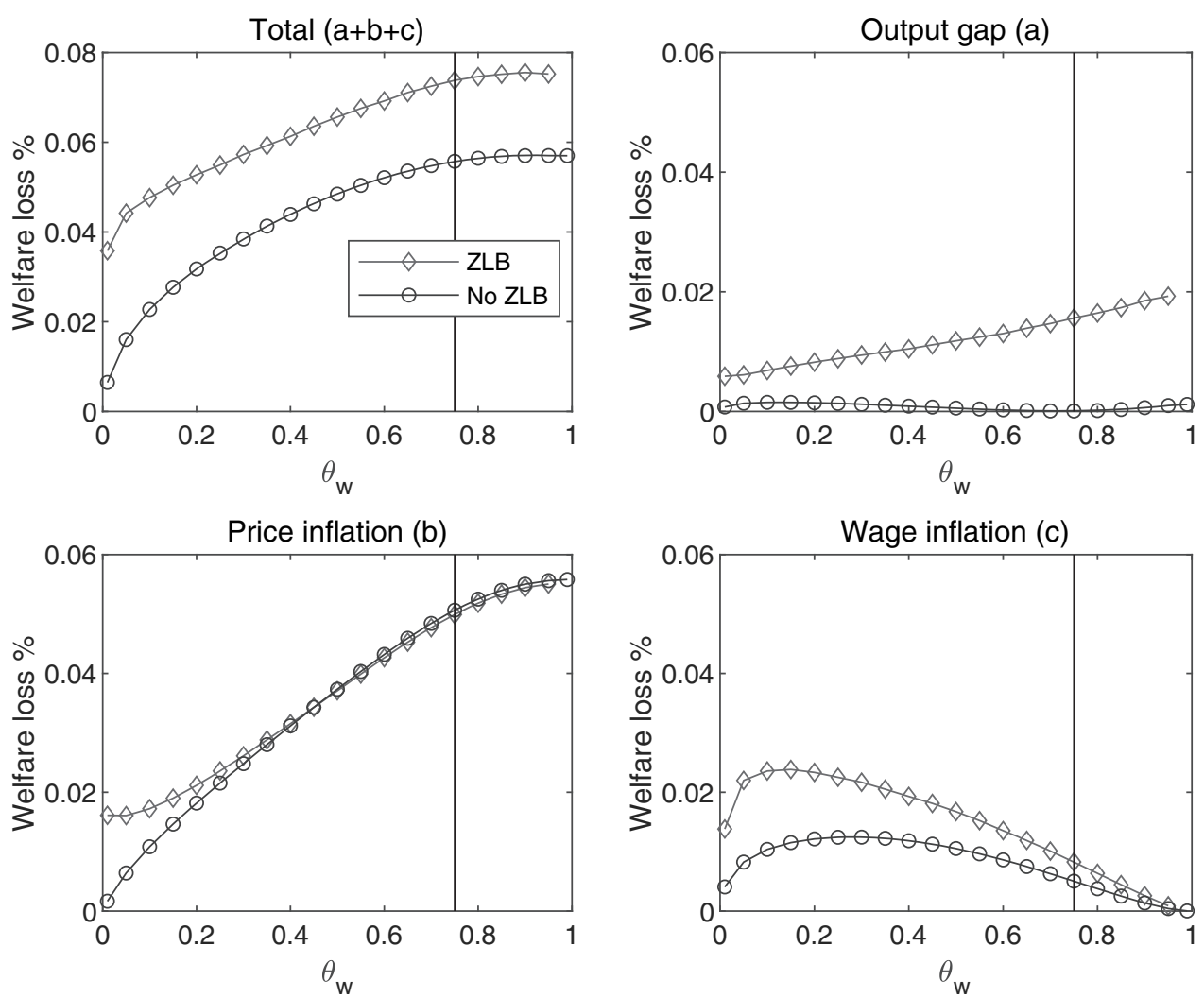

Figure 8 . Wage rigidities and welfare components: optimal policy and technology shocks

increase in wage flexibility, starting from the baseline value, partly offsets the larger costs resulting from the ZLB by reducing the volatility of the output gap (see top-right panel). But that beneficial impact of greater wage flexibility is more than offset by the increase in the costs resulting from greater volatility in price and wage inflation, as shown in the two bottom panels, accounting for the net increase in welfare losses.

In the case of an optimal policy under technology shocks our findings are somewhat different, as shown in Figure 8. In this case, and as discussed above, an increase in wage flexibility reduces welfare losses both with and without the ZLB constraint. The main difference, with respect to demand shocks, is that with technology shocks an increase in wage flexibility reduces the volatility of price inflation. In response to a positive technology shock, prices tend to go down, due to a fall in marginal costs, and wages tend to increase. Greater wage flexibility allows for larger wage raises and hence a smaller decline in marginal costs and prices, thus accounting for the smaller price inflation volatility associated with lower $\theta_{w}$ values. This effect contributes to the positive relation between wage rigidity and welfare losses. Note also that regarding total welfare losses, the slope of the two curves is similar with and without the ZLB constraint, suggesting that in this case, and in contrast with the cases considered previously, the presence of the ZLB constraint does not alter significantly the welfare impact of a change in wage flexibility. 


\section{Nominal rigidities, welfare and the zero lower bound}

Next we study the welfare effect of simultaneous changes in price and wage flexibility on welfare, and how those effects depend on the monetary policy regime and the presence or absence of a ZLB constraint.

Figure 9 shows the welfare loss from fluctuations in the economy, as a function of $\theta_{w}$ (line with blue circles) and as a function of $\theta$ (line with red diamonds). ${ }^{16}$ We use $\theta$ to denote a common value for $\theta_{w}$ and $\theta_{p} \cdot{ }^{17}$ The other parameters are kept at their baseline value. The figure shows outcomes without the ZLB constraint. The top panels show the outcome under a Taylor rule, conditional on demand shocks or technology shocks being the source of fluctuations. As discussed above, in both cases, an increase in wage flexibility leads to a deterioration in welfare for a large range of initial $\theta_{w}$ values. However, and starting from the baseline setting of 0.75 for $\theta$, a similar deterioration of welfare is obtained locally in response to a simultaneous increase in price and wage flexibility (i.e. a decrease in $\theta$ ). However, as the same graph reveals, the relation between welfare losses and nominal rigidities changes sign at relatively large values of $\theta$, implying that a non-trivial jointincrease in price and wage flexibility from their baseline value generates a welfare improvement.

The bottom-right panel of Figure 9 shows the corresponding outcome under the optimal policy when technology shocks are the source of fluctuations. ${ }^{18}$ In this case, and as discussed above, an increase in wage flexibility (while keeping $\theta_{p}$ constant) is welfare improving. Interestingly, as shown in Figure 9, that improvement vanishes (and becomes a welfare deterioration) when both prices and wages become more flexible (locally) starting from the baseline value for $\theta$. The reason is that both price and wage inflation become more volatile in that case (with and without the ZLB), offsetting the smaller losses due to a more stable output gap.

Next we show how the presence of a ZLB constraint affects the relation between welfare and nominal rigidities (i.e. price and wage rigidities, jointly). Figure 10 shows the welfare loss as a function of $\theta$, with and without a ZLB constraint. As shown in the top two panels, under a Taylor rule and conditional on either demand or technology shocks, the introduction of a ZLB constraint amplifies the increase in welfare losses from a (local) reduction in nominal rigidities. The ZLB constraint is also seen to increase the range of $\theta$ values for which welfare is reduced in response to a decrease in nominal rigidities, relative to the case without ZLB. The bottom-left panel shows the outcome under the optimal policy conditional on demand shocks. In contrast with the case of a change in wage flexibility only, discussed above in the context of Figure 4, now a welfare gain can be attained with a relatively small increase in both price and wage flexibility, starting from their baseline value. This is not the case when we condition on technology shocks (bottom-right panel):

\footnotetext{
${ }^{16}$ In the online appendix the reader can find 3D graphs showing welfare losses as a function of $\theta_{w}$ and $\theta_{p}$ (see Figure A3). We show the ZLB and no ZLB cases as separate graphs, because combining two 3D surfaces in the same graph would generate a visually confusing object which is difficult to interpret.

${ }^{17}$ As $\theta_{w}$ and $\theta_{p}$ share the same value in our baseline calibration, the vertical line in the figure indicates the baseline value of both these parameters.

${ }^{18}$ Welfare losses are zero with demand shocks as a source of fluctuations and in the absence of the ZLB, as reflected in the bottom-left panel of Figure 9.
} 

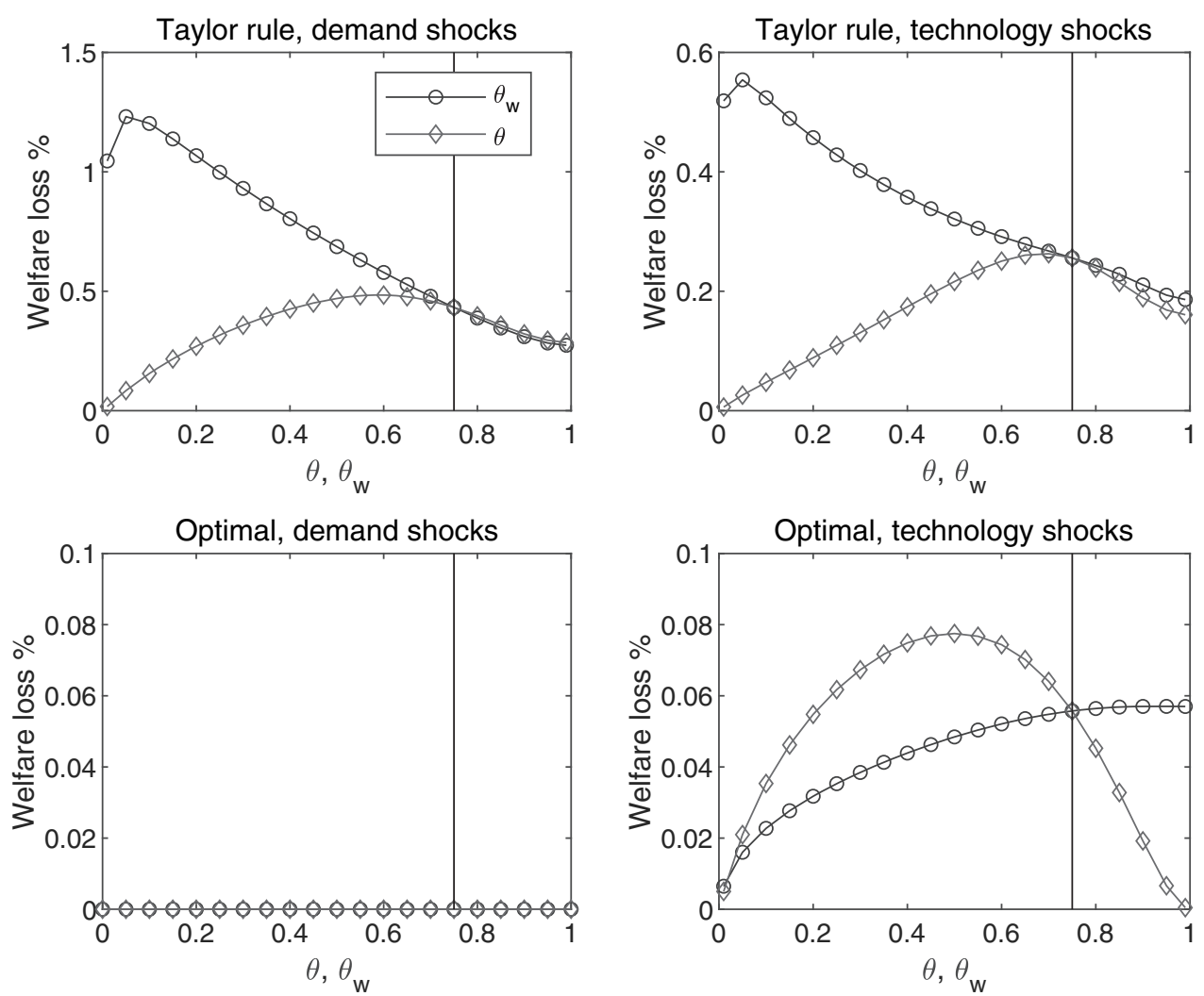

Figure 9. Nominal rigidities and welfare if zero lower bound absent

in that case, under the optimal policy, a small parallel increase in both wage and price flexibility from the baseline leads to a welfare deterioration, with and without a ZLB constraint.

Note finally that in the limit, if both prices and wages are fully flexible, the first best is attained with the resulting welfare losses being zero in all the scenarios considered. Accordingly, a sufficiently large joint increase in price and wage flexibility generates a welfare gain, independently of the monetary regime in place and the presence or absence of the ZLB constraint (because both become irrelevant for real allocations and welfare in the absence of nominal rigidities).

\section{Concluding remarks}

We have revisited the analysis in Galí (2013) on the welfare consequences of greater wage flexibility by explicitly taking into account the existence of a ZLB constraint on the nominal interest rate. In a first exercise, we have shown how a downward adjustment in labour costs (implemented through a wage subsidy) in a recessionary environment with a binding ZLB may (unintentionally) deepen the downturn, due to the implied procyclical response of the real interest rate. 

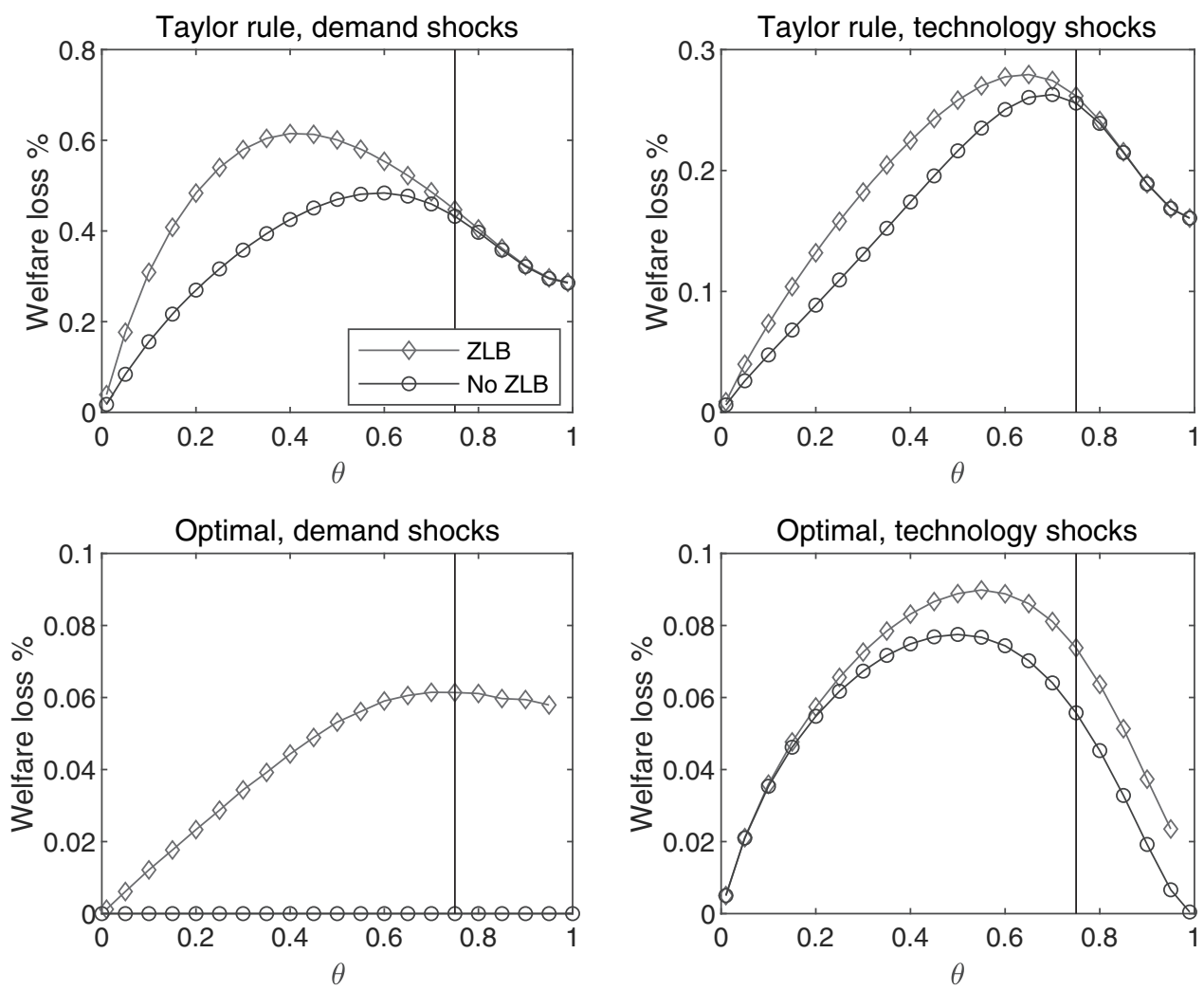

Figure 10. Nominal rigidities and welfare: effect of zero lower bound

We then have studied the impact of an occasionally binding ZLB constraint on the relationship between wage flexibility and the welfare costs of recurrent fluctuations. Several findings have emerged from our analysis. First, and perhaps not surprisingly, the presence of the ZLB increases welfare losses for any calibration of nominal rigidities and/or policy regime. Second, the main finding in Galí (2013), namely that under a (realistic) Taylor rule an increase in wage flexibility is welfare reducing, is robust to the presence of the ZLB constraint. Furthermore, we show that the ZLB constraint generally amplifies the adverse effects of greater wage flexibility on welfare. Third, when demand shocks are the driving force, an increase in wage flexibility is associated with larger welfare losses even when the central bank follows an optimal monetary policy. This is not true however for technology shocks. Finally, we have shown that under a Taylor rule and conditional on either demand or technology shocks, the introduction of the ZLB constraint: (i) amplifies the increase in welfare losses from a (local) simultaneous reduction in both price and wage rigidities; and (ii) increases the range of those rigidities for which welfare losses are decreasing in the degree of nominal rigidities, relative to the case without a ZLB constraint.

In summary, through the lens of the New Keynesian model the case for greater wage flexibility appears to be weaker than commonly held, and it is only weakened further by the introduction of an explicit ZLB constraint on the nominal interest rate. 


\section{Appendix: Optimal policy under commitment with a zero lower bound con- straint}

The problem of optimal policy with commitment is given by

$$
\min \frac{1}{2} E_{0} \sum_{t=0}^{\infty} \beta^{t}\left[\left(\sigma+\frac{\varphi+\alpha}{1-\alpha}\right) \tilde{y}_{t}^{2}+\frac{\epsilon_{p}}{\lambda_{p}}\left(\pi_{t}^{p}\right)^{2}+\frac{\epsilon_{w}(1-\alpha)}{\lambda_{w}}\left(\pi_{t}^{w}\right)^{2}\right]
$$

subject to equations (1)-(4) and $i_{t} \geqslant 0$.

Write the period Lagrangian

$$
\begin{aligned}
L_{t}= & \frac{1}{2}\left[\left(\sigma+\frac{\varphi+\alpha}{1-\alpha}\right) \tilde{y}_{t}^{2}+\frac{\epsilon_{p}}{\lambda_{p}}\left(\pi_{t}^{p}\right)^{2}+\frac{\epsilon_{w}(1-\alpha)}{\lambda_{w}}\left(\pi_{t}^{w}\right)^{2}\right]+\beta E_{t} V_{t+1} \\
& +m_{1 t}\left[y_{t}+\frac{1}{\sigma}\left(i_{t}-\rho-\left(1-\rho_{z}\right) z_{t}\right)\right]-\frac{1}{\beta} m_{1 t-1}\left(y_{t}+\frac{1}{\sigma} \pi_{t}^{p}\right) \\
& +m_{2 t}\left(\pi_{t}^{p}-\varkappa_{p} \tilde{y}_{t}-\lambda_{p} \tilde{\omega}_{t}\right)-m_{2 t-1} \pi_{t}^{p} \\
& +m_{3 t}\left(\pi_{t}^{w}-\varkappa_{w} \tilde{y}_{t}+\lambda_{w} \tilde{\omega}_{t}\right)-m_{3 t-1} \pi_{t}^{w} \\
& +m_{4 t}\left(\omega_{t}-\omega_{t-1}-\pi_{t}^{w}+\pi_{t}^{p}\right) .
\end{aligned}
$$

The Kuhn-Tucker conditions are

$$
\begin{gathered}
0=\frac{\partial L_{t}}{\partial y_{t}}=\left(\sigma+\frac{\varphi+\alpha}{1-\alpha}\right) \tilde{y}_{t}+m_{1 t}-\frac{1}{\beta} m_{1 t-1}-\varkappa_{p} m_{2 t}-\varkappa_{w} m_{3 t} \\
0=\frac{\partial L_{t}}{\partial \pi_{t}^{p}}=\frac{\epsilon_{p}}{\lambda_{p}} \pi_{t}^{p}-\frac{1}{\beta \sigma} m_{1 t-1}+m_{2 t}-m_{2 t-1}+m_{4 t} \\
0=\frac{\partial L_{t}}{\partial \pi_{t}^{w}}=\frac{\epsilon_{w}(1-\alpha)}{\lambda_{w}} \pi_{t}^{w}+m_{3 t}-m_{3 t-1}-m_{4 t} \\
0=\frac{\partial L_{t}}{\partial \omega_{t}}=\frac{\partial \beta E_{t} V_{t+1}}{\partial \omega_{t}}-\lambda_{p} m_{2 t}+\lambda_{w} m_{3 t}+m_{4 t} \\
0=\frac{\partial L_{t}}{\partial i_{t}} i_{t}=\frac{1}{\sigma} m_{1 t} i_{t}, \quad m_{1 t} \geqslant 0 \text { and } i_{t} \geqslant 0
\end{gathered}
$$

whereas the envelope condition gives

$$
\frac{\partial \beta E_{t} V_{t+1}}{\partial \omega_{t}}=-\beta E_{t} m_{4 t+1} .
$$

The equilibrium conditions under the optimal policy are then given by equations (1)-(4) and (A1)-(A5).

Final Manuscript Received: May 2020 


\section{References}

Adam, K. and Billi, R. (2006), 'Optimal monetary policy under commitment with a zero bound on nominal interest rates', Journal of Money, Credit and Banking, Vol. 38, pp. 1877-1905.

Adam, K. and Billi, R. (2007), 'Discretionary monetary policy and the zero bound on nominal interest rates', Journal of Monetary Economics, Vol. 54, pp. 728-752.

Aruoba, B. S., Cuba-Borda, P. Schorfheide, F. (2018), 'Macroeconomic dynamics near the ZLB: a tale of two countries', Review of Economic Studies, Vol. 85, pp. 87-118.

Bhattarai, S., Eggertsson, S. and Schoenle, R. (2018) 'Is Increased Price Flexibility Stabilizing (Redux)?' Journal of Monetary Economics, forthcoming.

Benhabib, J., Schmitt-Grohé, S. and Uribe, M. (2001), 'The perils of taylor rules', Journal of Economic Theory, Vol. 96, pp. 40-69.

Benhabib, J., Schmitt-Grohé, S. and Uribe, M. (2002), 'Avoiding liquidity traps', Journalof Political Economy, Vol. 110, pp. 535-563.

Benigno, G. and Fornaro, L. (2017), 'Stagnation traps', Review of Economic Studies, forthcoming.

Blanchard, O. J. and Galí, L. (2007), 'Real wage rigidities and the new keynesian model', Journal of Money, Credit, and Banking, 39, pp. 35-66.

Blanchard, O. J. and Galí, J. (2010), 'Labor markets and monetary policy: a new keynesian model with unemployment', American Economic Journal: Macroeconomics, Vol. 2, pp. 1-33.

Clarida, R., Galí, J. and Gertler, M. (2000), 'Monetary policy rules and macroeconomic stability: evidence and some theory', Quarterly Journal of Economics, Vol. 115, pp. 147-180

Christiano, L., Eichenbaum, M. and Rebelo, S. (2011), 'When is the government spending multiplier large?' Journal of Political Economy, Vol. 119, pp. 78-121.

Coibion, O., Gorodnichenko, Y. and Wieland, J. (2012), 'The optimal inflation rate in new keynesian models: should central banks raise their inflation targets in light of the zero lower bound?' Review of Economic Studies, Vol. 79, pp. 1371-1406.

Debortoli, D., Galí, J. and Gambetti, L. (2020), 'On the empirical (Ir)relevance of the zero lower bound constraint', NBER Macroeconomics Annual 2019, forthcoming.

De Long, J. B. and Summers, L. H. (1986), 'Is increased price flexibility stabilizing?' American Economic Review, Vol. 76, pp. 1031-44.

Eggertsson, G., and Woodford, M. (2003), 'The zero bound on interest rates and optimal monetary policy', Brookings Papers on Economic Activity, 1, pp. 139-211.

Eggertsson, G. (2010), The Paradox of Toil, unpublished manuscript.

Eggertsson, G. (2011), 'What fiscal policy is effective at zero interest rates?' NBER Macroeconomics Annual, Vol. 2010, pp. 59-112.

Eggertsson, G. and Krugman, P. (2012), 'Debt, deleveraging, and the liquidity trap: a fisher-minsky-koo approach', Quarterly Journal of Economics, Vol. 127, pp. 1469-1513.

Eggertsson, G., Ferrero, A. and Raffo, A. (2014), 'Can structural reforms help Europe?' Journal of Monetary Economics, Vol. 61, pp. 2-22.

Erceg, C. J., Henderson, D. W. and Levin, A. T. (2000), 'Optimal monetary policy with staggered wage and price contracts', Journal of Monetary Economics, Vol. 46, pp. 281-314.

Erceg, C. J., and Lindé J. (2012), 'Fiscal consolidation in an open economy', American Economic Review, Vol. 102, pp. 186-91.

Galí, J. (2013) Notes for a new guide to Keynes (I), wages, aggregate demand and employment', Journal of the European Econmic Association, Vol. 11, pp. 973-1003.

Galí, J. (2015) Monetary Policy, Inflation and the Business Cycle. An Introduction to the New Keynesian Framework, 2nd edition, Princeton University Press, Princeton, NJ.

Galí, J. and Monacelli, T. (2016), 'Understanding the gains from wage flexibility: the exchange rate connection', American Economic Review, Vol. 106, pp. 3829-3868.

Hall, R. (2005) Employment fluctuations with equilibrium wage stickiness', American Economic Review, Vol. 95, pp. 50-64.

Jung, T., Teranishi, Y. and Watanabe, T. (2005), 'Optimal monetary policy at the zero interest rate bound', Journal of Money, Credit and Banking, Vol. 37, pp. 813-835. 
Keynes, J. M. (1936), The General Theory of Employment, Interest and Money, MacMillan, London.

Liu, P., Theodoridis, K., Mumtaz, H. and Zanetti, F. (2019), 'Changing macroeconomic dynamics at the zero lower bound', Journal of Business and Economic Statistics, Vol. 37, pp. 391-404.

Mertens, K. R. S. and Ravn, M. O. (2014), 'Fiscal policy in an expectations-driven liquidity trap', Review of Economic Studies, Vol. 81, pp. 1637-1667.

Nakov, A. (2008), 'Optimal and simple monetary policy rules with a zero floor on the nominal interest rate', International Journal of Central Banking, Vol. 4, pp. 73-127.

Roulleau-Pasdeloup, J. and Zhutova, A. (2018), Labor Market Policies and the Missing Deflation Puzzle: Lessons from Hoover Policies during the Great Depression, unpublished manuscript.

Shimer, R. (2005), 'The cyclical behavior of equilibrium unemployment and vacancies', American Economic Review, Vol. 95, pp. 25-49.

Shimer, R. (2012), 'Wage rigidities and jobless recoveries', Journal of Monetary Economics, Vol. 59, pp. S65-S77.

Swanson, E. T., and Williams, J. C. (2014), 'Measuring the effect of the zero lower bound on medium- and longer-term interest rates', American Economic Review, 104, pp. 3154-3185.

Taylor, J. B. (1993), 'Discretion versus policy rules in practice', Carnegie-Rochester Series on Public Policy, Vol. 39, pp. 195-214.

Werning, I. (2011), Managing a Liquidity Trap: Monetary and Fiscal Policy, NBER WP \#17344

Zanetti, F. (2007), 'A non-walrasian labor market in a monetary model of the business cycle', Journal of Economic Dynamics and Control, Vol. 31, pp. 2413-2437

\section{Supporting Information}

Additional supporting information may be found in the online version of this article:

Online Appendix. Gains from Wage Flexibility and the Zero Lower Bound. 